\title{
Labyrinthe
}

$7 \mid 2000$

Numéro 7

\section{Les intellectuels français face aux crises du communisme en Europe du Centre-Est (1956-1981)}

Florence Grandsenne

\section{(2) OpenEdition}

12 Journals

Édition électronique

URL : http://journals.openedition.org/labyrinthe/731

DOI : 10.4000/labyrinthe.731

ISSN : 1950-6031

Éditeur

Hermann

Édition imprimée

Date de publication : 30 octobre 2000

Pagination : 164-166

Référence électronique

Florence Grandsenne, «Les intellectuels français face aux crises du communisme en Europe du Centre-Est (1956-1981)», Labyrinthe [En ligne], 7 | 2000, mis en ligne le 20 avril 2005, consulté le 19 avril 2019. URL : http://journals.openedition.org/labyrinthe/731 ; DOI : 10.4000/labyrinthe.731

Ce document a été généré automatiquement le 19 avril 2019

Propriété intellectuelle 


\title{
Les intellectuels français face aux crises du communisme en Europe du Centre- Est (1956-1981)
}

\author{
Florence Grandsenne
}

1 Lorsqu'en novembre 1956, les tanks soviétiques attaquèrent Budapest, le poète Pierre Emmanuel, constatant l'attrait que le communisme avait exercé jusqu'alors sur l'équipe de la revue Esprit, s'exclama : "Quelle déraison nous a menés là ? Quel somnambulisme? Par quel aveuglement avons-nous fait comme si le communisme n'était pas une névrose ?» Il y a effectivement une part de mystère, que tentent d'élucider actuellement les historiens, dans l'ampleur de l'attraction qu'a exercée le communisme sur l'intelligentsia française dans les années d'après-guerre et tout autant sur les causes et étapes de la désaffection dont ce système a fait ensuite l'objet.

2 Le travail de recherche mené ici participe de cette réflexion*. Il s'est donné pour but d'évaluer l'impact exercé sur l'itinéraire politique des intellectuels français par les trois principales crises qui secouèrent l'Europe du Centre-Est - trois mouvements de contestation brisés par trois coups de force : l'insurrection hongroise de 1956, le Printemps de Prague de 1968 et le mouvement polonais Solidarité de 1980-1981 -, afin de repérer si le processus de rejet du communisme par l'intelligentsia française fut le résultat de sa confrontation aux réalités de l'Est mises en évidence par ces trois moments clés.

3 Cette étude a permis tout d'abord d'évaluer l'écho respectif de ces trois crises : il fut très inégal. Le plus important fut celui provoqué par l'insurrection hongroise de 1956. La gauche, majoritaire alors dans le champ intellectuel français ${ }^{1}$, fut bouleversée par la répression soviétique. Le Parti communiste, qui avait approuvé celle-ci, vit bon nombre d'intellectuels quitter ses rangs ${ }^{2}$. Quant aux progressistes, beaucoup prirent parti en faveur du mouvement - qu'ils interprétaient comme une révolution anti-stalinienne en faveur d'un "vrai» communisme - et s'indignèrent de l'intervention armée. L'URSS perdit à leurs yeux l'aura acquise pendant la Seconde Guerre mondiale. 
4 Le Printemps de Prague, douze ans plus tard, ne suscita au contraire chez les intellectuels qu'un intérêt limité ; d'une part, parce que le mouvement tchécoslovaque fut totalement éclipsé par le mouvement de Mai 68 ; d'autre part, parce que le climat idéologique français, marqué par le réveil du messianisme révolutionnaire et la valorisation d'un marxisme dogmatique, greva la capacité de la gauche intellectuelle à comprendre la démarche des Tchécoslovaques.

5 L'écho de la crise polonaise fut beaucoup plus important. Beaucoup d'intellectuels français, en phase avec le mouvement Solidarité, se mobilisèrent pour sa défense. Cette attitude quasiment unanime tient à l'évolution idéologique qui s'était opérée dans l'intelligentsia depuis le milieu des années 70 . Le système communiste était perçu désormais comme un totalitarisme, et condamné au nom des droits de l'homme et de la démocratie.

6 Car il faut voir que, paradoxalement, ce ne sont pas ces trois crises qui ont constitué l'élément décisif mettant fin à l'attrait exercé par le communisme sur l'intelligentsia française. C'est en fait au milieu des années 70, sous l'influence de différents facteurs dont les échecs sanglants du communisme dans le Tiers-Monde et la découverte de la pensée de Soljenitsyne, qu'eut lieu la grande mutation idéologique des intellectuels.

7 Jusqu'alors en effet, beaucoup refusaient de juger le communisme à l'aune des réalités de l'Est, convaincus que ce n'était pas ce système qui fonctionnait dans ces pays, mais sa déviation, le stalinisme, et que celle-ci ne remettait pas en cause la validité de la doctrine marxiste. Les crises de 1956 et 1968 ne furent donc pas jugées comme réellement signifiantes et laissèrent apparemment intacte l'adhésion au projet communiste.

Apparemment seulement, car les textes montrent qu'en confrontant les intellectuels français aux réalités de la vie quotidienne à l'Est, elles alimentèrent un travail souterrain de réflexion, travail dont la cristallisation s'opéra au moment de la découverte par l'intelligentsia française de la pensée de Soljenitsyne.

9 C'est pourquoi lors de la crise polonaise, c'est un regard tout différent que les intellectuels français portèrent sur le système établi à l'Est ; convaincus désormais que le totalitarisme produit était inséparable de la théorie marxiste, ils rejetaient l'un et l'autre, au profit de la défense des droits de l'homme et de la démocratie.

\section{NOTES}

*. Synthèse de la thèse de doctorat réalisée par Florence Grandsenne à l'I.E.P. de Paris sous la direction de Serge Berstein et soutenue en mai 1998.

1. Il faut néanmoins noter l'existence d'un courant intellectuel très hostile au communisme, dont les personnalités les plus marquantes furent Albert Camus, François Mauriac, et Raymond Aron. Voir aussi l'étude sur la revue Preuves faite par Pierre Grémion, L'Intelligence de l'anticommunisme. Le Congrès pour la culture à Paris, 1950-1975, Paris, Fayard, 1995. 
2. Voir Jeannine Verdes-Leroux, Au service du Parti. Le parti communiste, les intellectuels et la culture (1944-1956), Paris, Fayard, 1983. 